
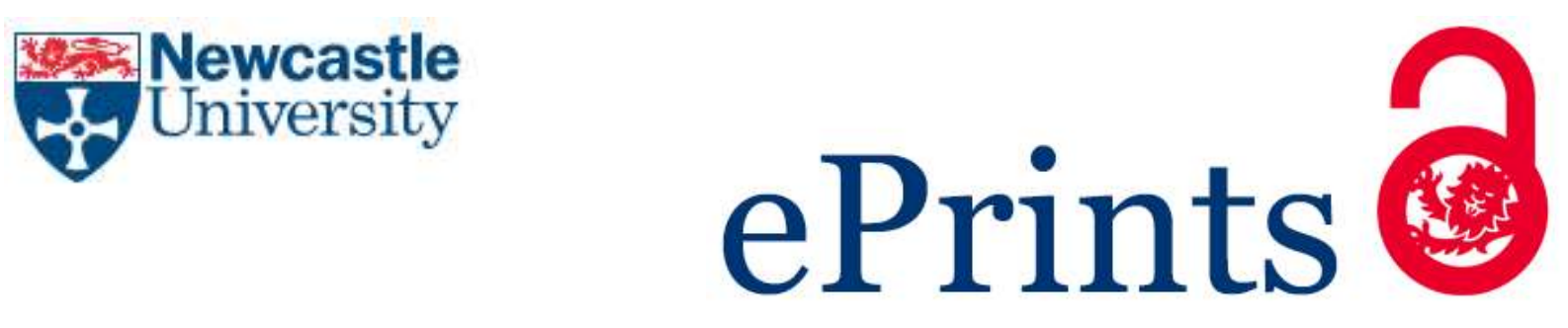

Jiang L, Wang RZ, Li JB, Wang LW, Roskilly AP. Performance analysis on a novel sorption air conditioner for electric vehicles. Energy Conversion and Management 2018, 156, 515-524.

\title{
Copyright:
}

(c) 2017. This manuscript version is made available under the CC-BY-NC-ND 4.0 license

DOI link to article:

https://doi.org/10.1016/i.enconman.2017.11.077

Date deposited:

$19 / 12 / 2017$

Embargo release date:

28 November 2018

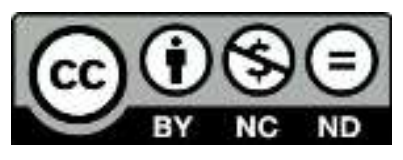

This work is licensed under a

Creative Commons Attribution-NonCommercial-NoDerivatives 4.0 International licence 


\title{
Performance analysis on a novel sorption air conditioner
}

\section{for electric vehicles}

\author{
L. Jiang ${ }^{\mathrm{a}, \mathrm{b}, *}$, R.Z. Wang ${ }^{\mathrm{a}}$, A.P. Roskilly \\ ${ }^{a}$ Institute of Refrigeration and Cryogenics, Shanghai Jiao Tong University, Shanghai, 200240, China \\ ${ }^{b}$ Sir Joseph Swan Centre for Energy Research, Newcastle University, Newcastle NE1 7RU, UK
}

Abstract: A novel sorption air conditioner for electric vehicles is presented, which is expected to reduce electricity consumption of on-board battery with a longer cruising mileage. This technology may be an alternative solution to conventional vapor compression air conditioner for current electric vehicles. Expanded natural graphite is selected in the development of composite sorbent. Performance of novel sorption air conditioner is analyzed based on sorption characteristic of composite sorbent, and a model electric car is chosen for detailed evaluation. It is indicated that sorption technology is able to be applied into electric vehicles. Energy density in winter and in summer ranges from $757 \mathrm{~kJ} \cdot \mathrm{kg}^{-1}$ to $1980 \mathrm{~kJ} \cdot \mathrm{kg}^{-1}$ and $387 \mathrm{~kJ} \cdot \mathrm{kg}^{-1}$ to $990 \mathrm{~kJ} \cdot \mathrm{kg}^{-1}$ whereas energy efficiency ranges from 0.34 to 0.82 and from 0.19 to 0.42 . Also worth noting that the extra mass of sorption air conditioner system will have limited influence on cruising mileage of electric vehicles, which results in a reduction less than $4.3 \%$. In winter, the highest saved cruising mileage by using novel sorption air conditioner is close to $100 \mathrm{~km}$. Even the lowest saved mileage in summer is still able to reach $21 \mathrm{~km}$, which is about $7.5 \%$ of the maximum mileage.

Keywords: Sorption; Air conditioner; Electric vehicles; Composite sorbent

* Corresponding author. Tel. +86-21-34206309

Email: maomaojianglong@sjtu.edu.cn (L. Jiang) 
$\mathrm{AC}$

$C D$

COP

D

ENG

EVs

F

GWP

GVs

$H D$

M

ODP

$P$

PTC

$Q$

R

S

$T$

24

$\Delta H$

$\Delta S$

$\eta$

25

\section{Subscripts}

a

am

b

c

con

eq
Air conditioner

Cold density $\left(\mathrm{kJ} \cdot \mathrm{kg}^{-1}\right)$

Coefficient of performance

Power density $\left(\mathrm{kW} \cdot \mathrm{kg}^{-1}\right)$

Expanded natural graphite

Electric vehicles

Driving resistance

Global warming potential

Gasoline vehicles

Heat density $\left(\mathrm{kJ} \cdot \mathrm{kg}^{-1}\right)$

Mass (kg)

Ozone depletion potential

Pressure $(\mathrm{Pa})$

Positive temperature coefficient

Heat (J)

Gas constant $\left(\mathrm{J} \cdot \mathrm{mol}^{-1} \cdot \mathrm{K}^{-1}\right)$

Cruising mileage $(\mathrm{km})$

Temperature $\left({ }^{\circ} \mathrm{C}\right)$

Reaction enthalpy of sorbent $\left(\mathrm{J} \cdot \mathrm{mol}^{-1}\right)$

Reaction entropy of sorbent $\left(\mathrm{J} \cdot \mathrm{mol}^{-1} \cdot \mathrm{K}^{-1}\right)$

Efficiency

Ambient

Ammonia

Battery

Cold

Condensation

Equilibrium 


$\begin{array}{ll}\text { eva } & \text { Evaporation } \\ \mathrm{H} & \text { High } \\ \mathrm{h} & \text { Heat } \\ \text { in } & \text { Input } \\ \mathrm{L} & \text { Low } \\ \text { max } & \text { Maximum } \\ \mathrm{mc} & \text { Mechanical and control } \\ \text { out } & \text { Output } \\ \mathrm{q} & \text { Discharge of battery } \\ \mathrm{R} & \text { Reaction } \\ \text { sorb } & \text { Sorbent } \\ \mathrm{T} & \text { Transmission }\end{array}$

\section{Introduction}

Energy specifically that from fossil fuels, is becoming increasingly scarce and expensive. It is extensively acknowledged that urban gasoline vehicles (GVs) have become a major source of energy consumption and pollution. To deal with this issue, electric vehicles (EVs) are considered as an alternative solution with few emission by using one or more electric motors for propulsion[1]. A long cruising mileage is expected as a ultimate goal for EVs in driving process with less consumption of on-board battery[2].

For GVs, a compressor driven by the engine is performed to realize air cooling in summer. In winter waste combustion heat diverted from engine cooling circuit could supply the heat to cabin inside. Different from internal combustion engines, considerable energy is consumed to heat the interior of EVs, which inevitably requires extra electricity up to $65 \%$ from vehicles' battery in term of various operating conditions[3]. Although part of the heat could be harvested from electric motor and battery, there remains to be a large demand of heating power supplied from on-board battery, which will decrease the overall driving range by up to $60 \%$ under typical standard heating conditions[4, 5]. In order to reduce the impact of air conditioner (AC) on battery in winter, current methods mainly lie in 42 positive temperature coefficient (PTC) heating[6], semiconductor heating[7] and vapor compression heat pump[8]. Although PTC heating has been commonly applied in commercial EVs, a large amount 
of electricity is consumed due to its relatively low energy efficiency, which sometimes results in lack of motivation. Considering semiconductor heating for EVs, there are several shortcomings e.g. low coefficient of thermoelectric materials and poor ideal cooling performance. Also worth noting that thermoelectric reactor production is limited by the production of thermoelectric elements. Comparably, vapor compression heat pump is more inclined to be selected for EVs due to its high heating efficiency. It seems to be flexibly adapted to different types of EVs with few modification, which was once regarded as a future developing trend of $\mathrm{AC}$ for EVs[9]. But in the case of low ambient temperature i.e. below $-10^{\circ} \mathrm{C}$, heating performance of vapor compression heat pump will be remarkably attenuated, which cannot meet heating requirements of EVs since evaporation temperature of refrigerant is too low $[10,11]$. When evaporator frosts in winter, heating performance will be further reduced with extra energy for defrosting, which also leads to safety problems in driving process[12]. In fact, vapor compression heat pump technology for EVs still needs to consume the electricity of on-board battery. Besides, most of the current researches of EVs focus on technology innovation to improve the capacity and efficiency of battery since battery is considered as the only energy resource. Nonetheless, it is admitted that heat and electricity load are often mutually independent, and electricity has a higher energy grade than heat. If electricity and heat can be charged and discharged respectively, vast potential working performance i.e. cruising mileage of EVs will be further explored. It is quite desirable to seek for an alternative method which could supply heat and cold without extra electricity consumption.

Sorption technology has been generally recognized as a prospective energy conversion method, which demonstrates various functions of refrigeration[13], heat pump[14], energy storage[15], carbon dioxide capture[16] and electricity generation[17]. Actually sorption refrigeration in GVs has been investigated theoretically and experimentally[18]. The core concept is to supply cooling power for vehicles through sorption systems driven by the exhaust heat of engine since waste combustion heat of GVs still has a high temperature[19]. Comparably, this could be completely different scenario for EVs, i.e. both heat and cold should be supplied with non-simultaneous heat input. Also no waste heat could be recovered to drive sorption system. To effectively overcome these difficulties, chemisorption AC could be a suitable candidate for EVs, which could flexibly adjusted to external conditions by using different metal halides due to its monovariant reaction process [20]. The intermittent operating mode and performance of heat and cold cogeneration[21] also meet the requirements, which simultaneously has a capability of energy storage[22]. Interaction between ammonia and metal halides is able to 
provide a remarkable energy potential in exothermic process. It is worth noting that heat e.g. electric heat could be charged through sorption reaction when battery charges the electricity. The discharging processes of electricity and heat are also independent. Advantages of chemisorption AC such as high energy density, long-term storage with little heat loss, time and space discrepancy adjustment happens to overcome the problems of $\mathrm{AC}$ for $\mathrm{EVs}$ [23]. High energy density is consistent with lightweight concept of EVs while time and space discrepancy adjustment with little heat loss provides more flexibilities for AC. Compared with conventional vapor compression AC for EVs, a main modification is that compressor is replaced with sorption reactor, and other equipment are remained. Various researchers have investigated working pairs for various types of sorption reactors[24]. One remarkable fact is that granular metal halides usually have low sorption and desorption capacity due to the fact that heat and mass transfer performance will be attenuated by swelling and agglomeration in working processes[25]. Small sorption and desorption capacity increase the required mass of sorbent, which will inevitably result in excessive loads for EVs. Composite sorbent is usually considered as a common solution to overcome drawbacks of granular metal halides by using various porous matrices[26], which provides the possibility of EVs' air conditioner for real applications[27].

Our previous research has initially verified the feasibility of such type AC for EVs by using sorption and desorption characteristics of multi-salt chemisorption working pairs. The research is to present and compare the possible heat and cold output for EVs without considering metal part of reactor [28]. Since rare related researches are reported in terms of sorption AC for EVs, this paper aims to investigate working performance of novel sorption $\mathrm{AC}$ for $\mathrm{EVs}$ in terms of theoretical thermodynamics and practical factors i.e. metal ratio, mileage, etc. Sorption and desorption characteristics of composite sorbent are also used for detailed analysis.

\section{Working principle of AC cycles for EVs}

For better elaboration of sorption $\mathrm{AC}$, conventional vapor compression $\mathrm{AC}$ for $\mathrm{EVs}$ is first introduced briefly as shown in Fig.1, which is mainly composed of a compressor, an evaporator, a condenser, a liquid receiver, and an expansion valve. Working process of conventional vapor compression AC is illustrated as follow: After expansion process of expansion valve, the refrigerant is evaporated in the evaporator, which will supply cooling power. Then the refrigerant vapor needs to be compressed to a higher pressure by a compressor and condensed in the condenser. In this process, part 
of electricity will be consumed through on-board battery which will inevitably reduce the cruising mileage of EVs. As mentioned above, vapor compression AC of commercial EVs is generally used for supply cooling power in summer. If it is required for heating, flow direction of the refrigerant is reversed and the condensation heat will be used.

\section{Compressor}

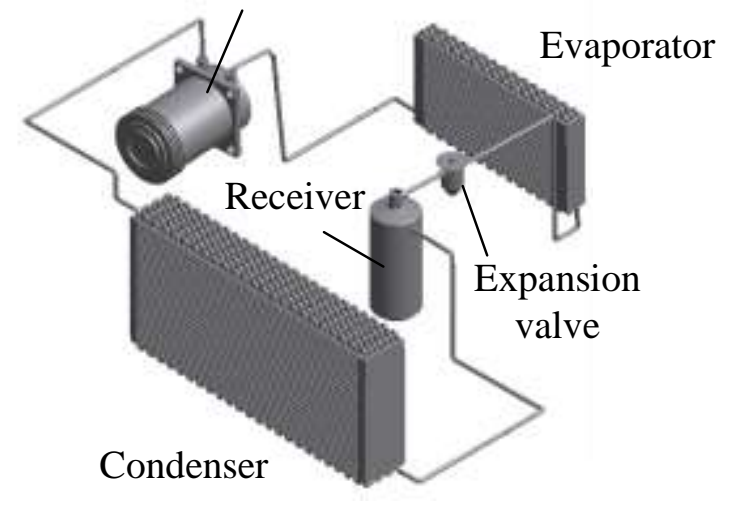

Fig.1. Conventional vapor compression AC for EVs.

Fig.2 indicates the basic principle of sorption AC, which could supply heat and cold, separately or heat and cold cogeneration. Sorption AC is composed of a sorption reactor, a condenser and an evaporator as shown in Fig.2a. Sorption reactor and condenser/evaporator i.e. liquid tank are connected with a mass channel and a refrigerant valve. In the charging process, sorption reactor is heated by external heat. Refrigerant is desorbed from sorption reactor to liquid tank, and then condensed by releasing its condensation heat to ambient heat sink. When charging process is finished, refrigerant valve between sorption reactor and liquid tank will be closed so that sorbent and refrigerant will be mutually separated. Thermal energy could be stored in form of chemical potential. Once heat and cold demands are required, refrigerant valve between sorption reactor and evaporator will open again. During the discharging process, liquid tank will be cooled to refrigeration temperature, and refrigerant evaporates and sorbed by sorption reactor. Evaporation latent heat of the refrigerant will supply useful cold for passengers inside the vehicles in summer while sorption heat could supply heat for passengers in winter.

In regard of chemisorption process, working pressure is determined by working temperature, which can be according to equation 1. On basis of this monovariant characteristic, sorption AC could be easily controlled and adapted to external heating and cooling conditions. Due to high reaction heat, 
ammonia working pairs will be selected for further elaboration. Fig.2b indicates $P-T$ schematic diagram of sorption AC. During the charging process, sorbent is heated from point D to point A. Refrigerant i.e. ammonia will be desorbed and flows into condenser. Desorption process happens from point A to point B. For real application, constraining temperature should be higher than $T_{\text {in }}$, which will result in a temperature driving potential. The higher driving temperature difference is, the faster desorption rate becomes. In the discharging process, evaporator is cooled from point $\mathrm{B}$ to point $\mathrm{C}$ whereas sorption reactor is cooled from point A to point D. Ammonia will be evaporated and then be sorbed by sorption reactor. Sorption process will proceed from point $\mathrm{C}$ to point $\mathrm{D}$. In this process, the stable cold and heat output could be obtained by adjusting the temperature of sorption reactor and evaporator.

$$
\operatorname{Ln}\left(P_{\text {eq }}\right)=-\frac{\Delta H_{\mathrm{R}}}{R T_{\text {eq }}}+\frac{\Delta S}{R}
$$

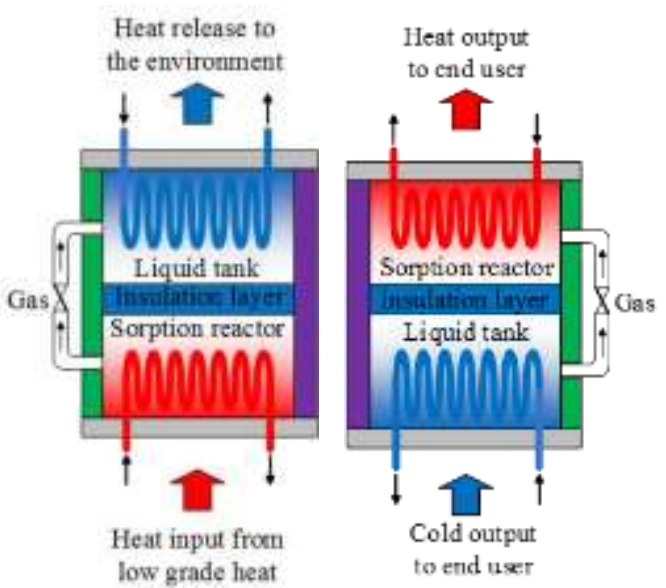

(a)

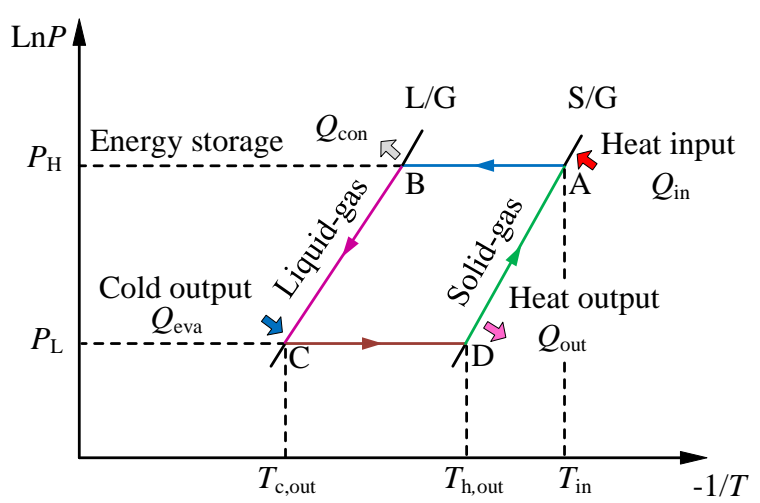

(b)

Fig.2. The basic principle of sorption AC (a) schematic; (b) $P$ - $T$ diagram. 

could come from electric heat or low grade heat. Thus temperature difference potential will promote the desorption of sorbent i.e. ammoniates. The desorbed ammonia is then condensed in the condenser by rejecting condensation heat to environmental heat sink. The ammonia liquid is gradually accumulated in the receiver.

(2) Sorption process for heat and cold output. Valve 2 is closed and valve 1 is open in this process. summer, sorption reactor will be cooled by ambient air outside EV and evaporator is circulated by

Fig.3. Novel sorption AC system for EVs.

It is widely recognized that sorption reactors has various types, which could be determined by sorbents and external heating conditions[29]. With regard to its specific application for EVs, sorption reactor is expected to be well designed. It will have a great influence on the performance of sorption $\mathrm{AC}$, which is worth elaborating in details. 
Fig.4a shows the reasonable schematic diagram of sorption reactor for the application of EVs, which is composed of several unit tubes as shown in Fig.4b. Staggered arrangement and aligned arrangement are two main arrangement methods for unit tubes, which have their respective advantages. For the better overall heat transfer coefficient of sorption reactor, staggered arrangement is applied to connect unit tubes[30]. For further optimizing heat transfer, it is desirable to enhance thermal conductivity of sorbents inside each unit tube due to the fact that large thermal contact resistance for sorbent side has become a remarkable barrier[31]. Thus composite sorbent developed with the matrix of expanded natural graphite (ENG) is selected and compressed into unit sorption tube with mass channel remained, which is verified to improve thermal conductivity of sorbent effectively.

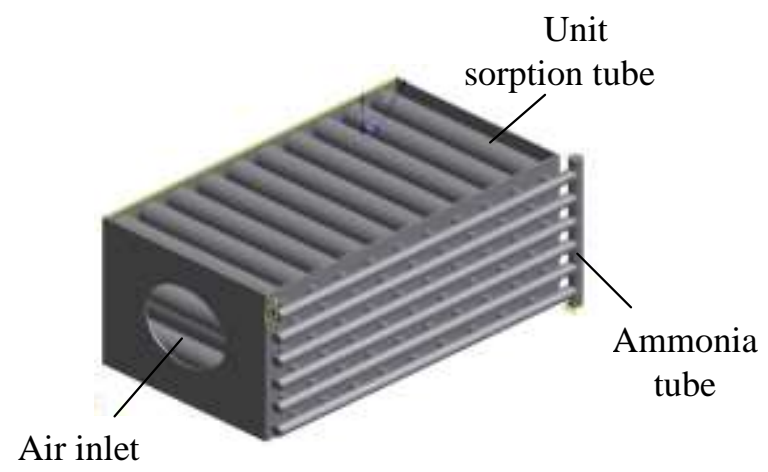

(a)

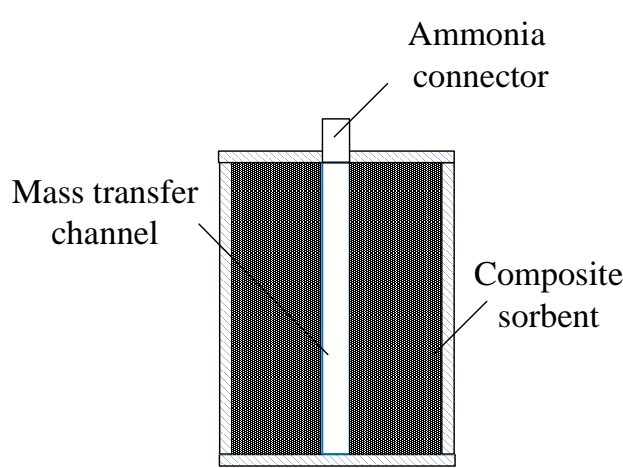

(b)

Fig.4. Sorption reactor of sorption AC system for EVs (a) schematic of sorption reactor;

(b) schematic of unit sorption tube.

\section{Evaluation of sorption AC for EVs}

Heat input of sorption AC for EVs in the charging process can be expressed as equation 2:

$$
Q_{\mathrm{h}, \mathrm{in}}=Q_{\mathrm{R}}+Q_{\text {sorbent }}+Q_{\text {reactor }}
$$

where $Q_{\mathrm{R}}$ is reaction heat, $Q_{\text {sorbent }}$ is sensible heat consumed by ammoniate, $Q_{\text {reactor }}$ is sensible heat consumed by metal part of sorption AC.

Heat output of sorption AC for EVs in winter can be expressed as equation 3:

$$
Q_{\mathrm{h}, \mathrm{out}}=Q_{\mathrm{R}}-Q_{\text {sorbent }}-Q_{\text {reactor }}
$$


Cold output of sorption AC for EVs in summer could be expressed as equation 4:

$$
Q_{\mathrm{c}, \mathrm{out}}=Q_{\mathrm{eva}}-Q_{\mathrm{am}}-Q_{\text {evaporator }}
$$

where $Q_{\mathrm{eva}}$ is evaporation heat of ammonia, $Q_{\mathrm{am}}$ is sensible heat of ammonia, $Q_{\mathrm{am}}$ is sensible heat consumed by metal part of evaporator when it is cooled from ambient temperature to evaporation temperature.

Heat density for heat output in winter could be expressed as equation 5:

$$
H D=\frac{Q_{\mathrm{h}, \text { out }}}{M_{\text {sorb }}}
$$

where $M_{\text {sorb }}$ is the mass of composite sorbent.

Heat efficiency for heat output in winter could be expressed as equation 6:

$$
C O P_{\mathrm{h}}=\frac{Q_{\mathrm{h}, \mathrm{out}}}{Q_{\mathrm{h}, \mathrm{in}}}
$$

Cold density for cold output in summer could be expressed as equation 7:

$$
C D=\frac{Q_{\mathrm{c}, \text { out }}}{M_{\mathrm{sorb}}}
$$

Cold efficiency for cold output in summer could be expressed as equation 8:

$$
C O P_{\mathrm{c}}=\frac{Q_{\mathrm{c}, \text { out }}}{Q_{\mathrm{h}, \mathrm{in}}}
$$

\section{Results and discussions}

\subsection{Theoretical performance of sorption AC}

Since more electricity is consumed in winter than in summer, theoretical heat density and heat efficiency of sorption AC are analyzed in terms of various sorption and resorption working pairs, which are comprehensively compared as shown in Fig.5. Fig.5a and Fig.5b indicate heat density and $C O P_{\mathrm{h}}$, and the sensible heat of salt is considered for analysis. The detailed evaluation method in this part could refer to the reference[32]. It is indicated that heat input temperature of sorption AC for EVs is less than $160^{\circ} \mathrm{C}$.With regard to heat density, one striking fact is that resorption working pairs have the same theoretical performance with that of sorption working pair. The highest theoretical heat density and 
heat output efficiency could reach $2178 \mathrm{~kJ} \cdot \mathrm{kg}^{-1}$ and 0.82 by using working pairs of $\mathrm{CaCl}_{2}-\mathrm{NH}_{3}$. This is mainly because $\mathrm{CaCl}_{2}$ proceeds two reaction processes in the selected temperature range. Under this scenario, reaction heat of two reaction processes will be used for evaluating energy density and efficiency. Also worth noting that resorption working pair is not suitable to be applied in EVs, which will result in larger required volume and mass by using two sorption reactors. Thus $\mathrm{CaCl}_{2}-\mathrm{NH}_{3}$ working pair will be selected for further evaluation due to its higher heat output performance.

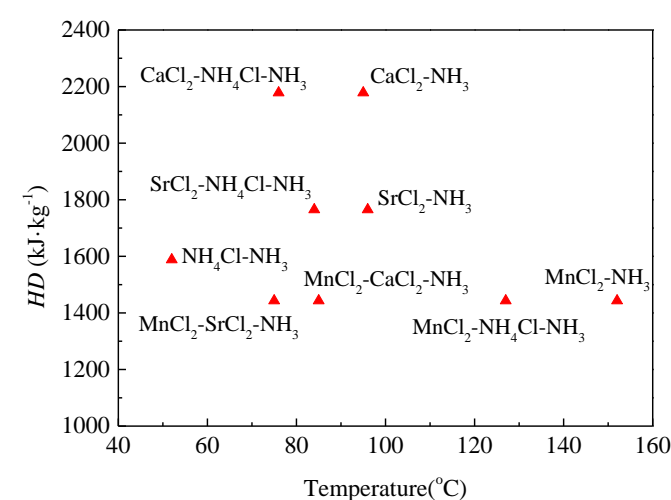

(a)

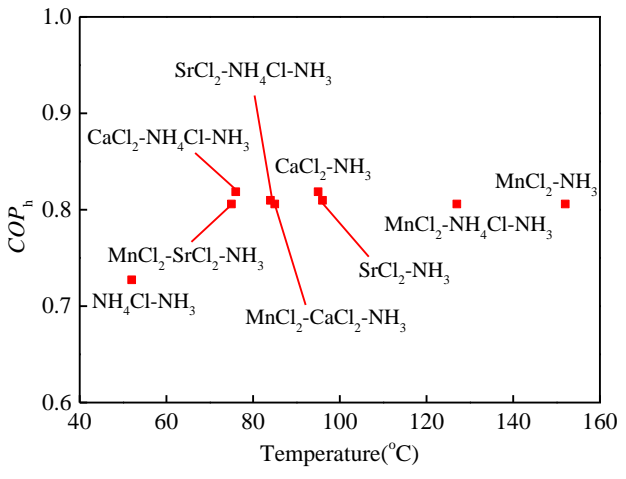

(b)

Fig.5. Theoretical heat density and $C O P_{\mathrm{h}}$ of sorption AC for EVs (a) heat density; (b) $C O P_{\mathrm{h}}$.

\section{Reaction processes of $\mathrm{CaCl}_{2}$ with ammonia could be according to equation from 9 to 11 . Table 1}

indicates the main parameters of $\mathrm{CaCl}_{2}$ in regard of $30^{\circ} \mathrm{C}$ heat sink temperature, which is composed of equilibrium desorption temperature, reaction enthalpy, reaction entropy and maximum cycle sorption capacity. To simplify the description of chemisorption processes, phrases of $\mathrm{CaCl}_{2} 8 / 4$ and $\mathrm{CaCl}_{2} 4 / 2$ are used in the rest of this paper. E.g. $\mathrm{CaCl}_{2} 4 / 2$ represents the process in which $\mathrm{CaCl}_{2}$ ammoniate reacts with ammonia from 2 moles to 4 moles.

$$
\mathrm{CaCl}_{2} \cdot 2 \mathrm{NH}_{3}+2 \mathrm{NH}_{3} \leftrightarrow \mathrm{CaCl}_{2} \cdot 4 \mathrm{NH}_{3}+2 \Delta H_{\mathrm{CaCl}_{2}}
$$

$$
\mathrm{CaCl}_{2} \cdot 4 \mathrm{NH}_{3}+4 \mathrm{NH}_{3} \leftrightarrow \mathrm{CaCl}_{2} \cdot 8 \mathrm{NH}_{3}+4 \Delta H_{\mathrm{CaCl}_{2}}
$$


Table 1. The main parameters of $\mathrm{CaCl}_{2}$ [33].

\begin{tabular}{ccccc}
\hline Sorbent & $\begin{array}{c}\text { Desorption } \\
\text { temperature }\left({ }^{\circ} \mathrm{C}\right)\end{array}$ & $\begin{array}{c}\text { Reaction enthalpy } \\
\left(\mathrm{J} \cdot \mathrm{mol}^{-1}\right)\end{array}$ & $\begin{array}{c}\text { Reaction entropy } \\
\left(\mathrm{J} \cdot \mathrm{mol}^{-1} \cdot \mathrm{K}^{-1}\right)\end{array}$ & $\begin{array}{c}\text { Maximum cycle sorption } \\
\text { capacity }\left(\mathrm{kg} \cdot \mathrm{kg}^{-1}\right)\end{array}$ \\
\hline $\mathrm{CaCl}_{2} 4 / 2$ & 97 & 42269 & 229.7 & 0.31 \\
$\mathrm{CaCl}_{2} 8 / 4$ & 86 & 41403 & 230.1 & 0.61 \\
\hline
\end{tabular}

229

In order to evaluate working modes of sorption $\mathrm{AC}$ of $\mathrm{EVs}, \mathrm{CaCl}_{2}-\mathrm{NH}_{3}$ working pair is exemplified under a selected condition i.e. $35^{\circ} \mathrm{C}$ condensation temperature and $5^{\circ} \mathrm{C}$ evaporation temperature in summer as well as $10^{\circ} \mathrm{C}$ condensation temperature and $0^{\circ} \mathrm{C}$ evaporation temperature in summer, which is shown in Fig.6. As analyzed above, $\mathrm{CaCl}_{2}$ proceeds two reaction processes, which means reaction will eventually proceed from $\mathrm{CaCl}_{2}$ 8/4 to $\mathrm{CaCl}_{2} 4 / 2$. For clear illustration of working process, summer and winter condition are elaborated separately.

During the charging process in summer, $\mathrm{CaCl}_{2}$ is heated by external heat with input temperature of $104^{\circ} \mathrm{C}$, which is determined by equation 1 in terms of $35^{\circ} \mathrm{C}$ condensation temperature. Since Fig.6 indicates the ideal thermodynamic process, heat input temperature is desorption temperature of $\mathrm{CaCl}_{2}$ 4/2 without considering temperature difference of heat transfer. Ammonia will be desorbed and condensed at a condensation pressure of $1.35 \mathrm{MPa}$ by releasing condensation heat to heat sink. During the discharging process in summer, evaporation heat of ammonia could supply cooling effect at an evaporation temperature of $5^{\circ} \mathrm{C}$. The concerning thermodynamic cycle is A-B-C-D-A, in which A-B represents charging process and $\mathrm{C}-\mathrm{D}$ denotes discharging process

Considering winter condition, heat input temperature of $\mathrm{CaCl}_{2}$ could be lower to $83^{\circ} \mathrm{C}$ in the charging process, which corresponds to condensation temperature of $10^{\circ} \mathrm{C}$. This process proceeds as A'-B'. In the discharging process, ammonia is also evaporated and sorbed by sorbent. Sorption heat of $\mathrm{CaCl}_{2}$ will be used to supply heat at a sorption temperature up to $74^{\circ} \mathrm{C}$, which corresponds to C'-D'. 
Sorption temperature reveals a capability of output temperature. It is usually supply heat of $25^{\circ} \mathrm{C}$ to cabin inside in winter. Thermodynamic cycle is A'-B'-C'-D'-A'. It is worth noting that thermodynamic cycle of sorption AC in summer will have a larger pressure difference between evaporation pressure and condensation pressure than that in winter, which will result in a higher energy efficiency of sorption AC system in winter than that in summer.

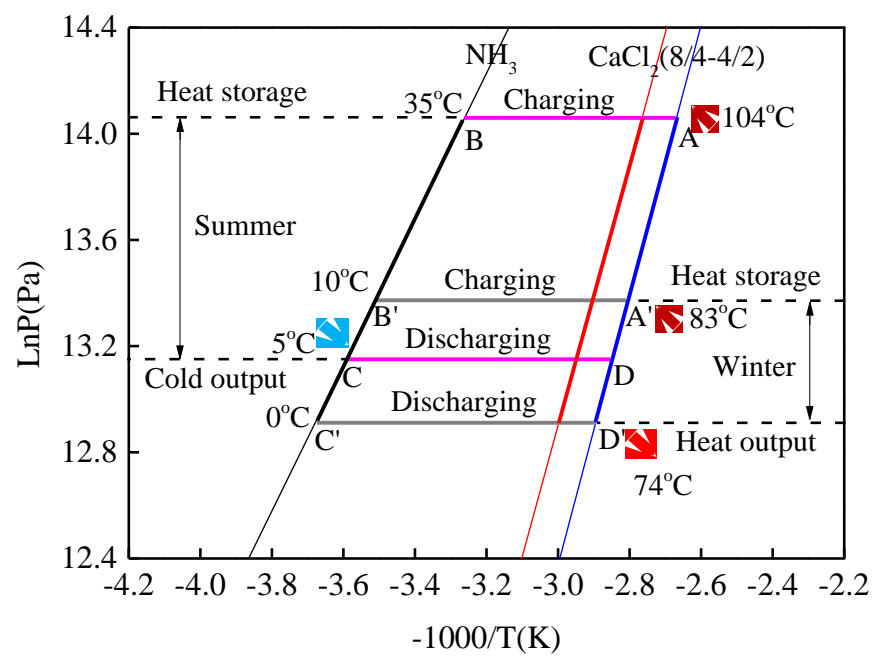

Fig.6. $P-T$ schematic diagram of sorption AC for EVs.

Global conversion rate is usually considered as a key parameter which represents the percentage of sorbent reacting with the refrigerant in the sorption and desorption process. It is recognized that global conversion rate is determined by various factors e.g. temperature and pressure potential. Before testing sorption characteristics, it is quite desirable to preliminary investigate the influence of global conversion rate on performance of sorption AC. Different global conversion rates of $\mathrm{CaCl}_{2}-\mathrm{NH}_{3}$ working pair are assumed, which range from 0.1 to 1 . The results are calculated based on each global conversion rate as shown in Fig.7. Fig.7a and Fig.7b demonstrate winter and summer condition respectively due to different heat and cold loads. It is indicated that energy efficiency is more sensitive 
to global conversion rate than energy density. When global conversion rate varies from 0.1 to 1.0 in winter condition, $C O P_{\mathrm{h}}$ increases remarkably from 0.075 to 0.82 , and heat density increases from 33 $\mathrm{kJ} \cdot \mathrm{kg}^{-1}$ to $1993 \mathrm{~kJ} \cdot \mathrm{kg}^{-1}$. Also in summer condition, $C O P_{\mathrm{c}}$ increases from 0.15 to 0.42 , and cold density increases from $201 \mathrm{~kJ} \cdot \mathrm{kg}^{-1}$ to $1003 \mathrm{~kJ} \cdot \mathrm{kg}^{-1}$.

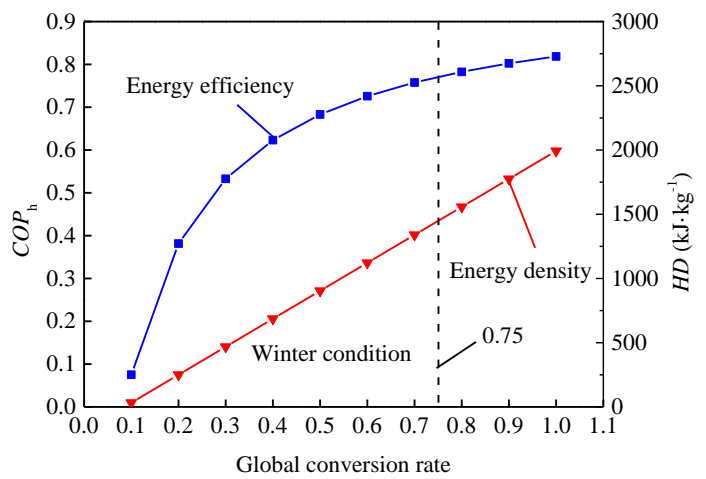

(a)

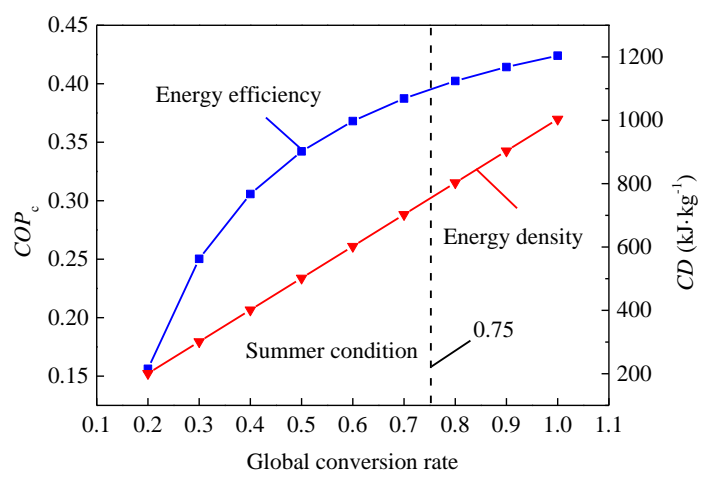

(b)

Fig.7. Theoretical energy density and COP of sorption AC vs. different global conversion rates

(a) winter condition; (b) summer condition.

\subsection{Performance analysis based on sorption characteristics and thermal capacity}

For theoretical analysis, global conversion rate is able to reach $100 \%$ with an infinite reaction time and large temperature and pressure differential potential. Nonetheless, a full global conversion rate could rarely be achievable with limited time and temperature difference. Thus experimental global conversion rate will be significant for comprehensive evaluation of sorption AC. The concerning experimental sorption characteristics are investigated in terms of different evaporation temperatures and condensation temperatures in summer and in winter, which are shown in Fig.8 and Fig.9, respectively. The detailed testing process by using a specially designed experimental unit could be referred to our previous work[34]. Composite $\mathrm{CaCl}_{2}$ is developed with $\mathrm{ENG}$ as porous matrix for heat 
and mass transfer enhancement. Different from desorption temperature of $104^{\circ} \mathrm{C}$ and $83^{\circ} \mathrm{C}$, heat input temperature of composite $\mathrm{CaCl}_{2}$ is selected as $120^{\circ} \mathrm{C}$ for testing, which considers heat transfer resistance and enough temperature driving potentials. This selected temperature is exemplified for investigating the performance in terms of different evaporation and condensation temperatures. Also electrical heat and possible low grade heat could be utilized, which results in less energy input.

For winter condition, evaporation temperature is chosen in the range from $-15^{\circ} \mathrm{C}$ to $10^{\circ} \mathrm{C}$ and sorption temperature is taken as $25^{\circ} \mathrm{C}$. For summer condition, condensation temperature is controlled from $20^{\circ} \mathrm{C}$ to $45^{\circ} \mathrm{C}$, and evaporation temperature is $5^{\circ} \mathrm{C}$.

It is demonstrated that global conversion rate and sorption capacity increase with the increase of evaporation temperature. This is because global conversion rate is mainly determined by pressure potential between constraining evaporation pressure and theoretical equilibrium pressure. The higher evaporation temperature is, a larger pressure potential could become, which will result in higher global conversion. Similar reason could also explain the pressure potential between constraining condensation pressure and theoretical equilibrium pressure. Global conversion rate increases from 0.66 to 0.99 as evaporation temperature varies from $-15^{\circ} \mathrm{C}$ to $10^{\circ} \mathrm{C}$, which covers most of ambient temperature ranges in winter. Results indicate that composite $\mathrm{CaCl}_{2}$ could reach a maximum ammonia sorption capacity of $0.9 \mathrm{~kg} \cdot \mathrm{kg}^{-1}$ at an evaporation temperature of $10^{\circ} \mathrm{C}$, which accounts for about $99 \%$ of the maximum theoretical sorption capacity. Also worth noting global conversion rate and sorption capacity increase with the decrease of condensation temperature. One remarkable fact is sorption capacity is more sensitive to condensation temperature when compared with evaporation temperature. Sorption capacity ranges from $0.56 \mathrm{~kg} \cdot \mathrm{kg}^{-1}$ to $0.9 \mathrm{~kg} \cdot \mathrm{kg}^{-1}$, which accounts for $61.4 \%$ to $98.7 \%$ of the maximum theoretical sorption capacity. Our previous research revealed that granular $\mathrm{CaCl}_{2}$ merely reached up to 


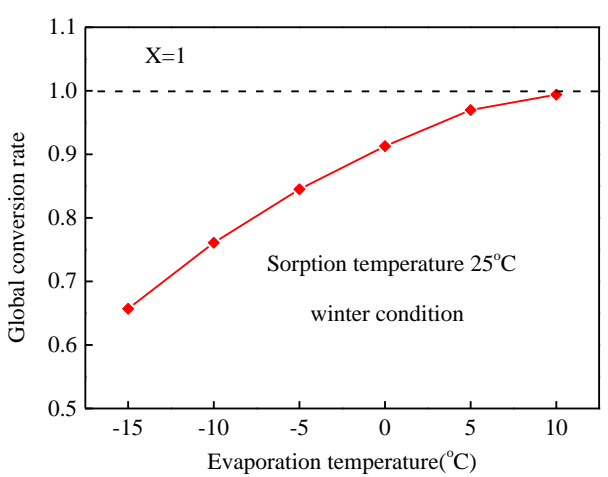

(a)

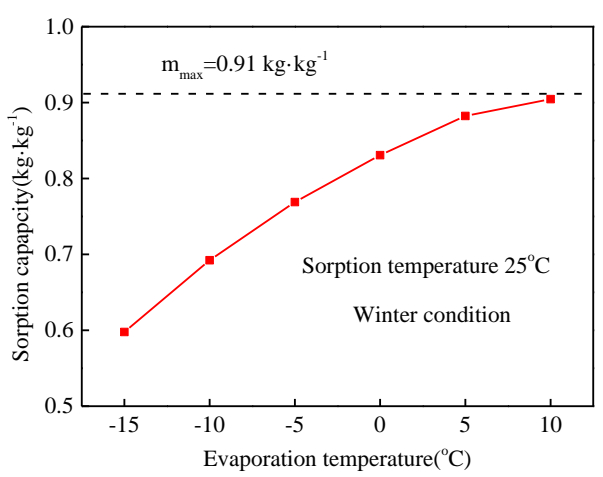

(b)
308

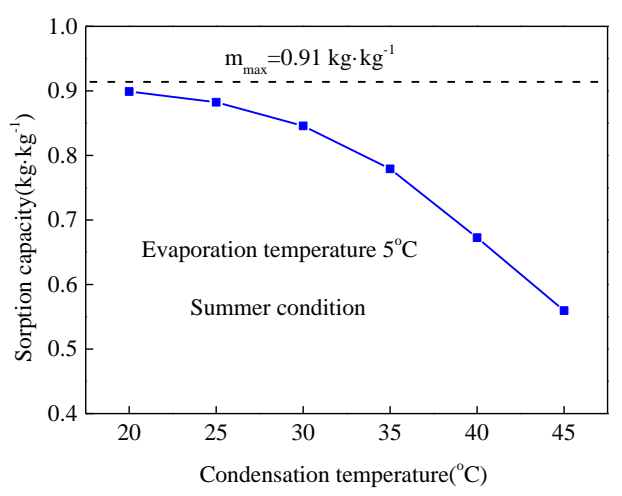

(b)

(a)

Fig.9. Sorption characteristics of composite $\mathrm{CaCl}_{2}-\mathrm{NH}_{3}$ vs. different condensation temperatures in 
analyzed and compared in terms of different mass ratios between composite sorbent and metal part. For evaluating energy efficiency and density, sensible heat of the reactor will be considered due to the fact that metal part will play a negative role on cruising mileage of EVs. Fig.10 indicates $C O P_{\mathrm{h}}$ and heat density with regard to winter condition. It is worth noting that energy efficiency and energy density increase with the increase of evaporation temperature in winter. Energy efficiency increases more sharply than that of energy density due to the fact that the extra heat loss of metal part. It is also indicated that the highest $C O P_{\mathrm{h}}$ and heat density could reach 0.82 and $1980 \mathrm{~kJ} \cdot \mathrm{kg}^{-1}$, respectively when evaporation temperature is $10^{\circ} \mathrm{C}$ in winter. For mass ratio from 0 to $12, C O P_{\mathrm{h}}$ and heat density range from 0.34 to 0.82 and $757 \mathrm{~kJ} \cdot \mathrm{kg}^{-1}$ to $1980 \mathrm{~kJ} \cdot \mathrm{kg}^{-1}$ when evaporation temperature increases from $-15^{\circ} \mathrm{C}$ to $10^{\circ} \mathrm{C}$. It is demonstrated that heat density is relatively higher than cold density. This could be attributed to the fact that heat output is provided by sorption heat which is much higher than evaporation latent heat for cold output. Also in summer, energy efficiency and density increase with the decrease of condensation temperature, which is shown in Fig.11. For different condensation temperatures and mass ratios, $C O P_{\mathrm{c}}$ and cold density range from 0.19 to 0.42 and $387 \mathrm{~kJ}^{\mathrm{kg}} \mathrm{kg}^{-1}$ to 990 $\mathrm{kJ} \cdot \mathrm{kg}^{-1}$, respectively. Considering theoretical analysis, mass ratio between sorbent and metal part is usually considered as 0 or 1 , which will lead to a relatively high energy output. Comparably, mass ratio of real sorption system is usually higher than 3 , and this ratio is possible to be reached with the improved manufacturing technology and optimized design of reactor.

In order to have a comprehensive understanding of sorption AC technology, mass ratio is defined as 3 to assess its influence on EVs. A model EV i.e. IONIO Electric is selected for further illustration, which is produced by Hyundai. The weight of this EV is about $1880 \mathrm{~kg}$ with a battery of $28 \mathrm{~kW} \cdot \mathrm{h}$, which could reach a maximum mileage of $280 \mathrm{~km}$ in summer. This model has a generalized meaning 


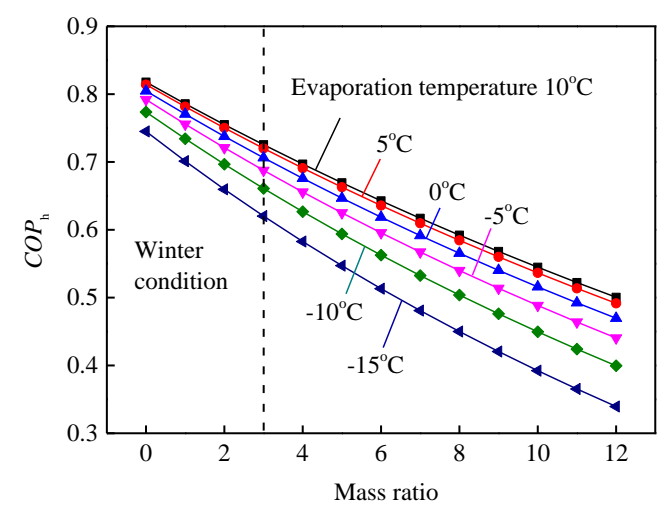

(a)

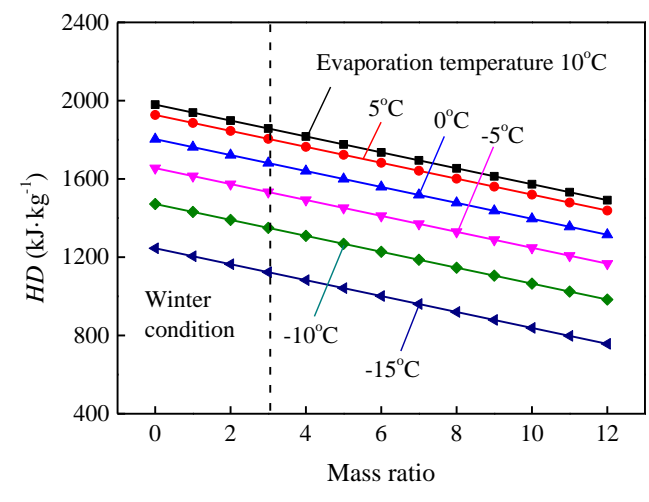

(b)

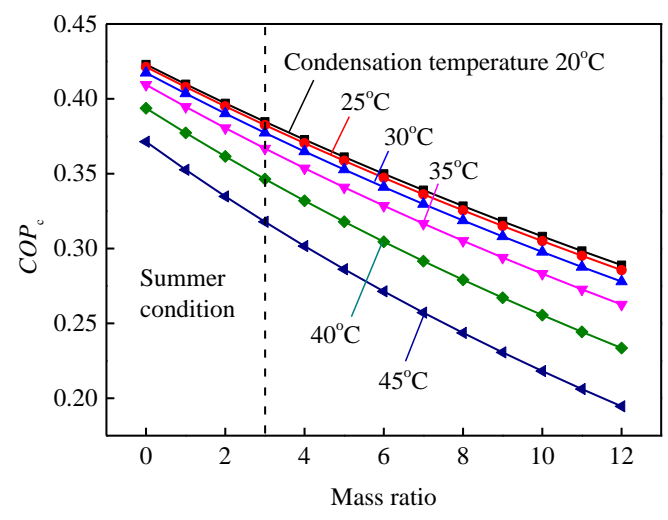

(a)

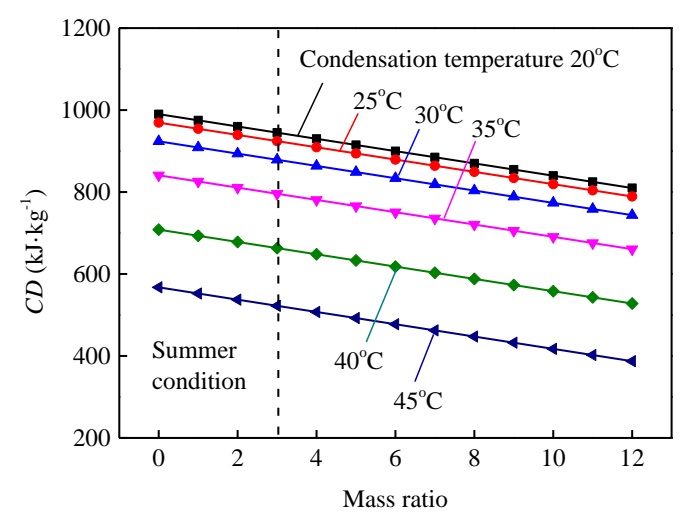

(b)

Fig.11. $C O P_{\mathrm{c}}$ and cold density vs. different mass ratios in summer (a) $C O P_{\mathrm{c}}$; (b) cold density. 


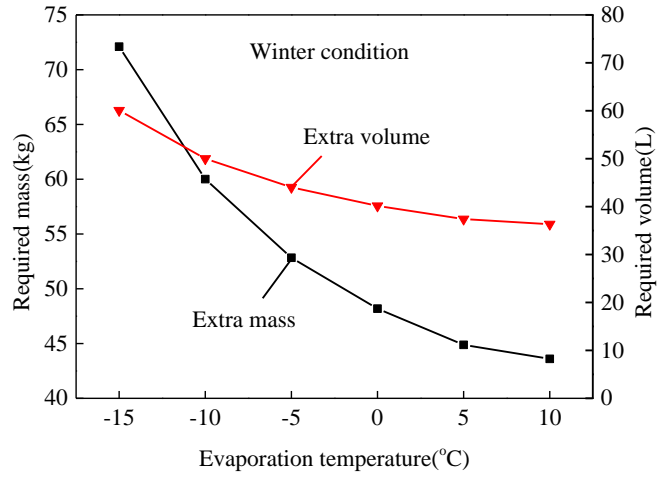

(a)

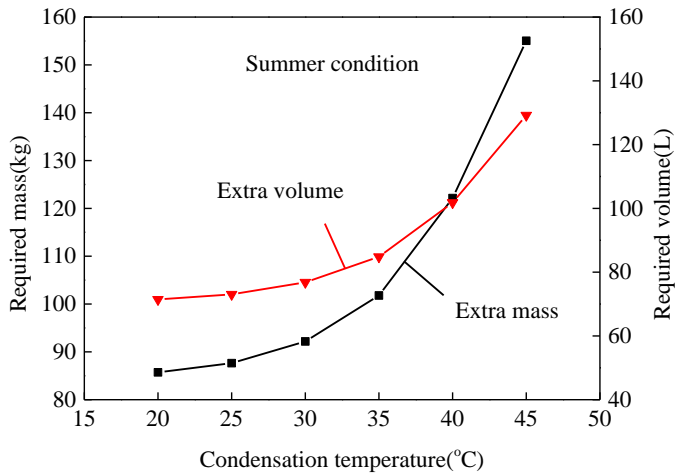

(b)

Fig.12. Extra required mass and volume of sorption AC system for EVs (a) in winter; (b) in summer. 
process can be expressed as equation 12[36]:

$$
S=\frac{M_{\mathrm{b}} D_{\mathrm{b}} \eta_{\mathrm{q}} \eta_{\mathrm{mc}} \eta_{\mathrm{T}}}{F}
$$

where $M_{\mathrm{b}}$ is mass of battery, $D_{\mathrm{b}}$ is power density of battery, $\eta_{\mathrm{q}}$ is discharge efficiency of battery, $\eta_{\mathrm{mc}}$ is mechanical and control efficiency, $\eta_{\mathrm{T}}$ is transmission efficiency, $F$ is driving resistance, which is mainly composed of friction and air resistance. summer when considering $20 \%$ energy consumption of the battery i.e. cruising mileage of selected model EV could reach up to $350 \mathrm{~km}$ without using AC. With regard to winter condition, at least $30 \%$ of electricity will be consumed for heating in terms of various operating conditions[12]. 30\% of electricity consumption is selected for further evaluation, thus the maximum mileage of model EV in winter could reach $245 \mathrm{~km}$. Due to the extra mass of system and varied sorption capacities, the maximum mileage cannot achieved. Therefore, Fig.13 demonstrates the cruising mileage of model EV and its concerning reduction under different operating conditions when considering the extra mass of sorption AC system. to $2.4 \%$ when compared with the maximum value of $245 \mathrm{~km}$. Mileage of EV in summer ranges from $271.1 \mathrm{~km}$ to $268 \mathrm{~km}$ with reduction from $3.1 \%$ to $4.3 \%$. One remarkable fact is that the extra mass of sorption system will have limited influence on cruising mileage of EV. The reason is elaborated as follow: The extra mass mainly affects friction which is a part of driving resistance according to equation 12. Also worth noting friction coefficient is quite low, which results in small increment for 


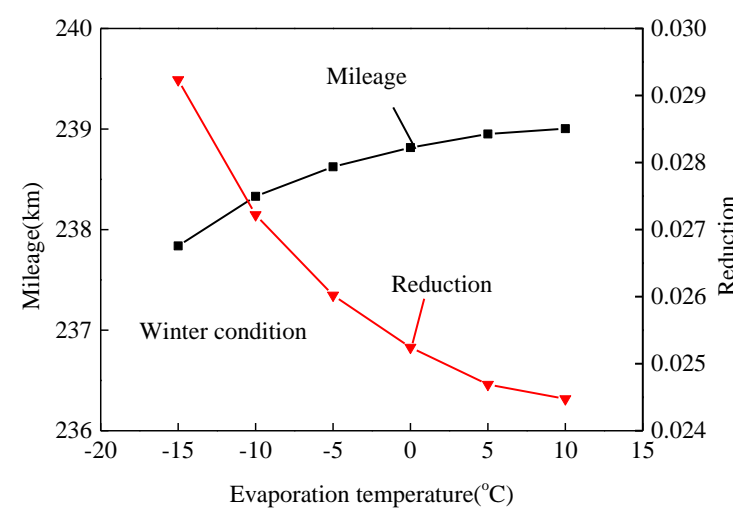

(a)

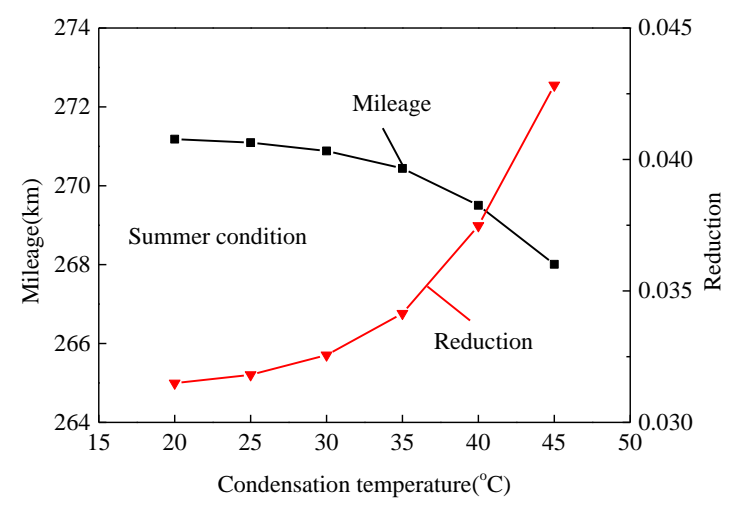

(b)

Fig.13. Cruising mileage of selected model EV and its reduction caused by extra mass 


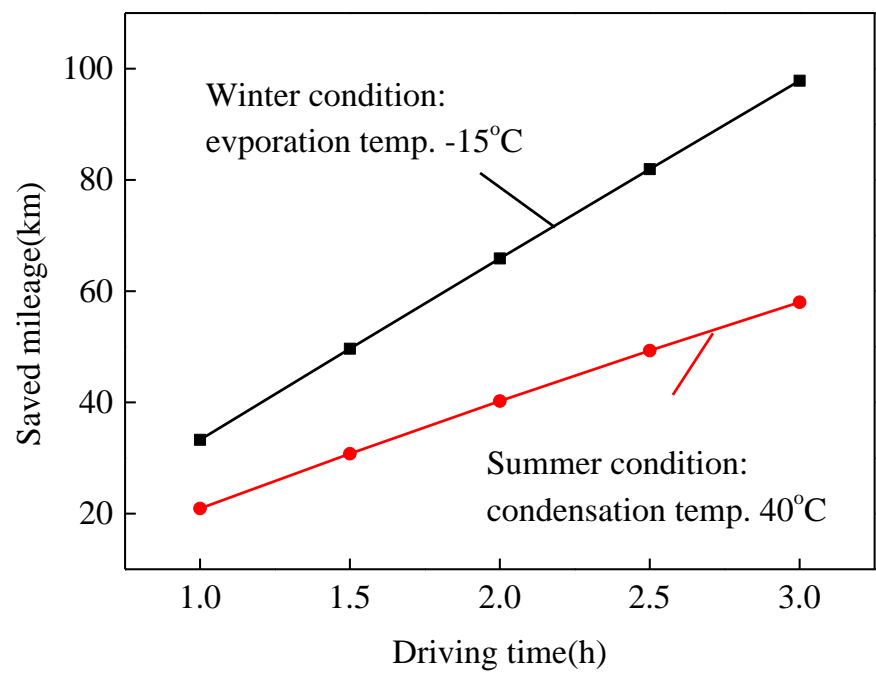

399

400

401

402

403

404

405

406

407

408

409

410

411

412

413

414

Table 2 demonstrates a comprehensive comparison between novel sorption AC system and conventional vapor compression AC system for EVs in terms of refrigerant, system compactness, energy source, mechanical stability, supply capacity, performance, cruising mileage and cost.

A controversial issue of sorption AC system is that ammonia is used as working fluid. Compared with Freon for vapor compression AC, ammonia is an environmental-benign refrigerant with zero ozone depletion potential (ODP) and global warming potential (GWP). It is admitted that ammonia is hazardous when it reaches a certain concentration. However, Freon could also be toxic under a high concentration. System maintenance and good design are considered as the solution, and then safety of sorption AC for EVs could be ensured. Also pungent smell of little ammonia could serve as a reminder for passengers inside EVs.

It is demonstrated that vapor compression AC for EVs is more compact than sorption AC since mass and volume of sorption reactor are larger than that of compressor. Nonetheless, there remains to be enough space under the bonnet of EVs, which could be used for placing sorption reactor. Thus the increased mass and volume of sorption AC is acceptable since there is no change to EVs' appearance. 
modes are proposed. One is that electricity is used to charge on-board battery and sorption AC, which doesn't change the current charging mode by using the same socket of EVs in charging station or other places with charging piles. It is quite convenient for users, but energy utilization efficiency is relatively low. The other is that low grade heat could be used for charging heat of sorption AC, which are independent of charging electricity for EVs. The advantage is that a higher system efficiency could be obtained. Charging station should also be reconstructed for the application of low grade heat. not so much comparability since the charging source and effect produced are different. the selected EV model based on Chinese market price, cost of compressor is about 1500 RMB. For a accounts for 500 RMB, metal part costs about 2000 RMB, and valves cost about 500 RMB. Thus initial cost of sorption AC will be 1500 RMB higher than that of vapor compression AC. The initial cost will 


\begin{tabular}{ccc}
\hline Type & Vapor compression & Sorption \\
Refrigerant & Freon & Ammonia \\
System compactness & High & Moderate \\
Energy source & Electricity & Electricity/low grade heat \\
Mechanical stability & High & High \\
Supply capacity & Desirable & Desirable \\
Thermodynamic & High & Moderate \\
performance & Standard & At least 30\% higher \\
Cruising mileage & Standard & \\
Cost & & Less $5 \%$ increment of the cost of EV \\
\hline
\end{tabular}

\section{Conclusions}

A novel sorption AC is presented and designed to reduce electricity consumption of on-board battery for EVs. It is considered to be an alternative solution to conventional vapor compression AC, which aims to achieve a longer cruising mileage. Performance of sorption AC is analyzed in terms of energy density, energy efficiency, extra mass and saved mileage. Conclusions are yielded as follows:

(1) Resorption working pairs have a same theoretical performance with that of sorption working 
(2) Global conversion rate and sorption capacity increase with the increase of evaporation temperature and the decrease of condensation temperature. Global conversion rate of composite $\mathrm{CaCl}_{2}$ increases from 0.66 to 0.99 as evaporation temperature varies from $-15^{\circ} \mathrm{C}$ to $10^{\circ} \mathrm{C}$ in winter. Composite $\mathrm{CaCl}_{2}$ can reach a maximum ammonia sorption capacity of $0.9 \mathrm{~kg} \cdot \mathrm{kg}^{-1}$ at an 
473

474

475

476

477

478

479

480

481

482

483

484

485

486

487

on-board battery could be recovered as a part of heating. Thus the best solution is the combination of battery cooling system and sorption AC system. Both electricity and low grade heat could be used in the charging process to further improve energy efficiency.

Acknowledgements: This research was supported by National Natural Science Foundation of China under contract number (51606118), foundation for Innovative Research Groups of National Natural Science Foundation of China (51521004) and Heat-STRESS project (EP/N02155X/1) funded by Engineering and Physical Science Research Council of the UK.

\section{References}

[1] Alves J, Baptista PC, Gonçalves GA, Duarte GO. Indirect methodologies to estimate energy use in vehicles: Application to battery electric vehicles. Energy Conversion and Management. 2016;124:116-29.

[2] Godina R, Rodrigues EMG, Paterakis NG, Erdinc O, Catalão JPS. Innovative impact assessment of electric vehicles charging loads on distribution transformers using real data. Energy Conversion and Management. 2016;120:206-16.

[3] Chiu C-C, Tsai N-C, Lin C-C. Near-optimal order-reduced control for A/C (air-conditioning) system of EVs (electric vehicles). Energy. 2014;66:342-53.

[4] Smith WJ. Can EV (electric vehicles) address Ireland's $\mathrm{CO}_{2}$ emissions from transport? Energy. 2010;35(12):4514-21.

[5] Krzesińska M, Lachowski AI. Elastic properties of monolithic porous blocks of compressed expanded graphite related to their specific surface area and pore diameter. Materials Chemistry and Physics. 2004;86(1):105-11.

[6] Jin X, Li J-q, Zhang C-n, Wu P-e. Researches on Modeling and Experiment of Li-ion Battery PTC 
Self-heating in Electric Vehicles. Energy Procedia. 2016;104:62-7.

[7] Dai X, Wang Y, Wu Y, Luo H, Liu G, Li D, et al. Reliability design of direct liquid cooled power semiconductor module for hybrid and electric vehicles. Microelectronics Reliability. 2016;64:474-8.

[8] Jung J, Jeon Y, Lee H, Kim Y. Numerical study of the effects of injection-port design on the heating performance of an R134a heat pump with vapor injection used in electric vehicles. Applied Thermal Engineering. 2017;127:800-11.

[9] Lee D-Y, Cho C-W, Won J-P, Park YC, Lee M-Y. Performance characteristics of mobile heat pump for a large passenger electric vehicle. Applied Thermal Engineering. 2013;50(1):660-9.

[10] Qin F, Shao S, Tian C, Yang H. Experimental Investigation on Heating Performance of Heat Pump for Electric Vehicles in Low Ambient Temperature. Energy Procedia. 2014;61:726-9.

[11] Qin F, Xue Q, Albarracin Velez GM, Zhang G, Zou H, Tian C. Experimental investigation on heating performance of heat pump for electric vehicles at $-20^{\circ} \mathrm{C}$ ambient temperature. Energy Conversion and Management. 2015;102:39-49.

[12] Qi Z. Advances on air conditioning and heat pump system in electric vehicles - A review.

Renewable and Sustainable Energy Reviews. 2014;38:754-64.

[13] Jiang L, Lu YJ, Tang K, Wang YD, Wang R, Roskilly AP, et al. Investigation on heat and mass transfer performance of novel composite strontium chloride for sorption reactors. Applied Thermal Engineering. 2017;121:410-8.

[14] Freni A, Maggio G, Sapienza A, Frazzica A, Restuccia G, Vasta S. Comparative analysis of promising adsorbent/adsorbate pairs for adsorptive heat pumping, air conditioning and refrigeration. Applied Thermal Engineering. 2016;104:85-95.

[15] Gaeini M, Zondag HA, Rindt CCM. Effect of kinetics on the thermal performance of a sorption 
heat storage reactor. Applied Thermal Engineering. 2016;102:520-31.

[16] Zhao R, Deng S, Zhao L, Liu Y, Tan Y. Energy-saving pathway exploration of CCS integrated with solar energy: Literature research and comparative analysis. Energy Conversion and Management. 2015;102:66-80.

[17] Jiang L, Wang LW, Liu CZ, Wang RZ. Experimental study on a resorption system for power and refrigeration cogeneration. Energy. 2016;97:182-90.

[18] Tamainot-Telto Z, Metcalf SJ, Critoph RE. Novel compact sorption generators for car air conditioning. International Journal of Refrigeration. 2009;32(4):727-33.

[19] Sharafian A, Bahrami M. Critical analysis of thermodynamic cycle modeling of adsorption cooling systems for light-duty vehicle air conditioning applications. Renewable and Sustainable Energy Reviews. 2015;48(Supplement C):857-69.

[20] Bao H, Ma Z, Roskilly AP. Integrated chemisorption cycles for ultra-low grade heat recovery and thermo-electric energy storage and exploitation. Applied Energy. 2016;164:228-36.

[21] Jiang L, Roskilly AP, Wang RZ, Wang LW, Lu YJ. Analysis on innovative modular sorption and resorption thermal cell for cold and heat cogeneration. Applied Energy. 2017;204:767-79.

[22] Cabeza LF, Solé A, Barreneche C. Review on sorption materials and technologies for heat pumps and thermal energy storage. Renewable Energy. 2017;110:3-39.

[23] Jiang L, Wang L, Wang R, Zhu F, Lu Y, Roskilly AP. Experimental investigation on an innovative resorption system for energy storage and upgrade. Energy Conversion and Management. 2017;138:651-8.

[24] Frazzica A, Freni A. Adsorbent working pairs for solar thermal energy storage in buildings.

Renewable Energy. 2017;110:87-94. 
541

542

543

544

545

546

547

548

549

550

551

552

553

554

555

556

557

558

559

560

561

562

[25] Al-Mousawi FN, Al-Dadah R, Mahmoud S. Low grade heat driven adsorption system for cooling and power generation using advanced adsorbent materials. Energy Conversion and Management. 2016;126:373-84.

[26] Jiang L, Wang LW, Jin ZQ, Wang RZ, Dai YJ. Effective thermal conductivity and permeability of compact compound ammoniated salts in the adsorption/desorption process. International Journal of Thermal Sciences. 2013;71:103-10.

[27] Wang LW, Bao HS, Wang RZ. A comparison of the performances of adsorption and resorption refrigeration systems powered by the low grade heat. Renewable Energy. 2009;34(11):2373-9.

[28] Wang LW, Jiang L, Gao J, Gao P, Wang RZ. Analysis of resorption working pairs for air conditioners of electric vehicles. Applied Energy. 2017. available online.

[29] Jiang L, Lu YJ, Tang K, Wang YD, Wang R, Roskilly AP, et al. Investigation on heat and mass transfer performance of novel composite strontium chloride for sorption reactors. Applied Thermal Engineering. 2017;121(Supplement C):410-8.

[30] Gao P, Zhang XF, Wang LW, Wang RZ, Li DP, Liang ZW, et al. Study on $\mathrm{MnCl}_{2} / \mathrm{CaCl}_{2}-\mathrm{NH}_{3}$ two-stage solid sorption freezing cycle for refrigerated trucks at low engine load in summer. Energy Conversion and Management. 2016;109:1-9.

[31] Miles DJ, Shelton SV. Design and testing of a solid-sorption heat-pump system. Applied Thermal Engineering. 1996;16(5):389-94.

[32] Li T, Wang R, Kiplagat JK. A target-oriented solid-gas thermochemical sorption heat transformer for integrated energy storage and energy upgrade. AIChE Journal. 2013;59:1334-47.

[33] Jiang L, Wang LW, Zhou ZS, Zhu FQ, Wang RZ. Investigation on non-equilibrium performance of composite adsorbent for resorption refrigeration. Energy Conversion and Management. 
564 [34] Jiang L, Wang RZ, Lu YJ, Roskilly AP, Wang LW, Tang K. Investigation on novel modular 565 sorption thermal cell with improved energy charging and discharging performance. Energy Conversion 566 and Management. 2017;148:110-9.

567 [35] Jiang L, Wang LW, Wang RZ. Investigation on thermal conductive consolidated composite $\mathrm{CaCl}_{2}$

568 for adsorption refrigeration. International Journal of Thermal Sciences. 2014;81:68-75.

569 [36] Yu ZS. Automotive Theory: China Machine PRESS, 2012.

570 